\title{
Cidadania, Modernidade e Gestão do Trabalho no Brasil'
}

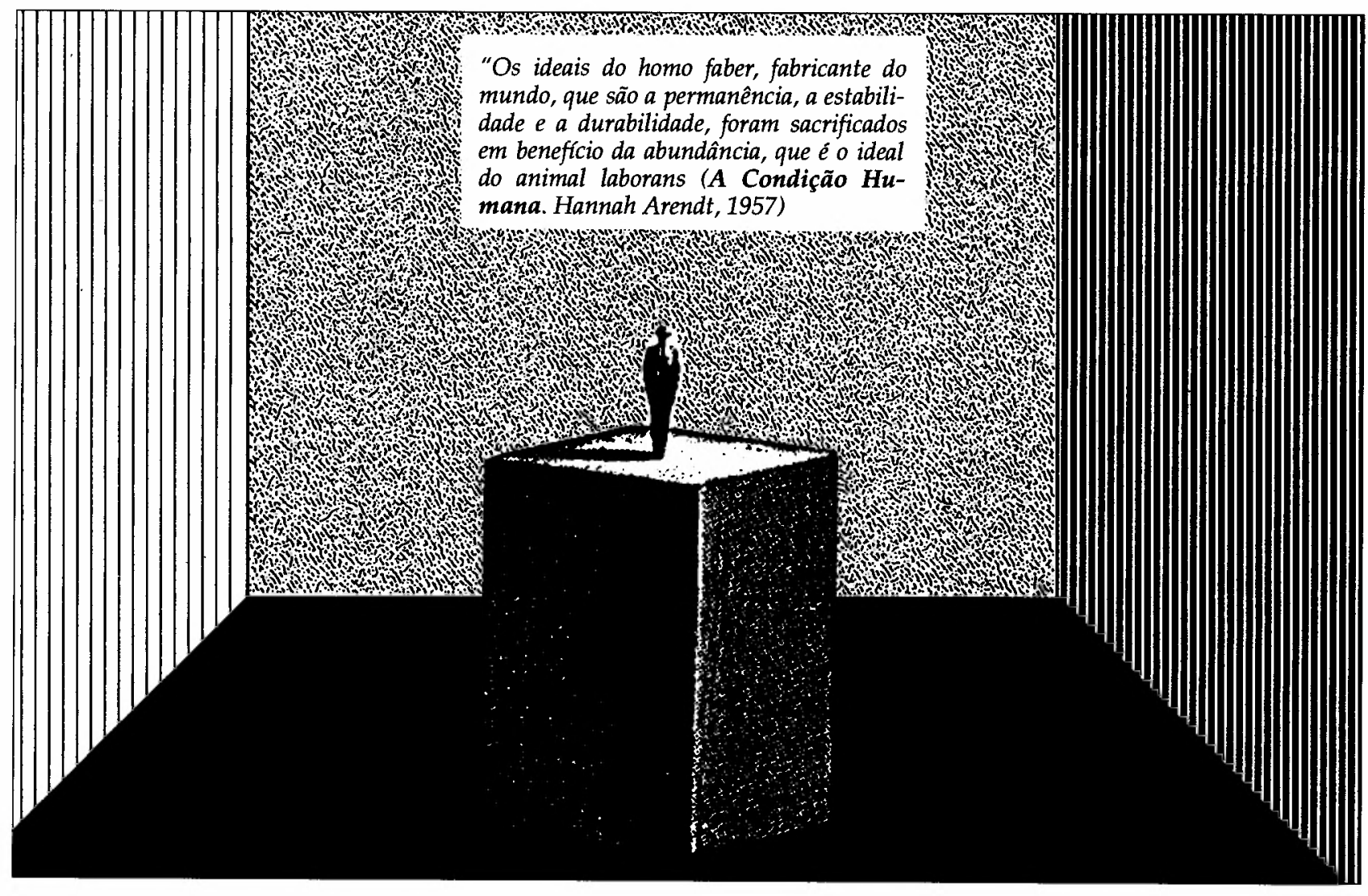

Ricardo Toledo Neder

Professor do Departamento de Fundamentos Sociais e Juridicos da Administração/EAESP/FGV.

* RESUMO: O ponto central de discussão nesse artigo reside na relação positiva entre a constituição de uma nova cidadania no País e as práticas de gestão social em organizações sob processo de modernização. Considerando que a "modernidade" não é, isoladamente, inovações organizacionais e realização de mudanças tecnológicas, são exploradas as dimensões da gestão social do trabalho que presidem conflitos e novos processos de envolvimento das pessoas, com ênfase em um estudo de caso. Sem inovações efetivas nas práticas de gestão social, redundam em fracasso estratégias de mudança da base técnica (associadas ou não a inovações organizacionais, do tipo JIT/Kanban, etc.).

* PALAVRAS-CHAVE: Cidadania; Inovações na Gestão Social do Trabalho; Novo Quadro de Relações entre Trabalhadores, Estado e Empresários no Brasil; Modernização Técnica.
* ABSTRACT: The main issue of this paper is related to two aspects: the shaping of a new citizenship and the management "praxis" of social features of the labour relations in Brazil. Assuming that there is a causal link between these two aspects, the author also proposes a concept of "social management" to understand management and technological changes in organizations. Without effective social changes (related with a new citizenship) in the field of labour process and relations, technical or managerial reforms tend to be a failure.

* KEY WORDS: Social Management of Labour Process and Relations; Citizenship and Labour Relations in Brazil; Modernization and Political Participation.

1. Esse texto integra capítulo da tese de doutorado em andamento; apresentei versão inicial no seminário internacional "Modernización empresarial y Cambios en Relaciones Industriales en Paises de America Latina y Europa", organizado pela Universidad Nacional de Colômbia $e$ Colégio de México. Bogotá/Colômbia; abril de 1991. 
2. A expressāo "cidadania regulada" aplica-se ao arranjo político das relaçōes entre o Estado, empresariado e trabalhadores que viabilizou 0 salto desenvolvimentista entre as décadas de 50 e 70 , entrando em declínio aberto nos anos 80 . Sob tal "ordem" políticoinstitucional, tornar-se assalariado equivalia à aquisiçāo de deveres no sentido de contribuir obrigatoriamente para a manutenção do sistema sindical, previdenciário e de benefícios aposentadoria, sob a custódia do Estado. Em contrapartida, foi se consolidando um ordenamento jurídicoformal e de práticas trabahistas - convertidos em direitos do trabalhador capaz de estabelecer "reservas de mercado" às diferentes profissões, por meio sistema de representação sindical - 0 "sindicato úniCo". Acerca da cidadania regulada ver CARONE, E. Movimento Operário no Brasil (1964-84), Sāo Paulo. Ed. Difel. 1984; SANTOS, Wanderley G. dos. "A Pós-"Revolução" Brasileira" in Var. Aut., Brasil Sociedade Democrática. Rio de Janeiro, Ed. J. Olimpio, 1985; e BOSCHI, R. "Entre a Cruz e a Caldeira: Classes Médias e Política na Terra da Transição". In LARANGEIRA, S. (Org.) Classes Sociais $e$ Movimentos Sociais na América Latina. São Paulo. Ed. Hucitec. 1990.

3. Segundo um analista internacional, as novas ondas administrativas apontam para três aspectos carregados de problematicidade: 0 tratamento improvisado dos aspectos políticos; a conceituação inadequada de termos-chave, tais como cultura; e a falta de pesquisa sistemática e a natureza anedótica de muitos dos dados que sustentam as novas teorias administrativas além da forma recorrente pela qual esse número ex tremamente limitado de exemplos aparece. WOOD, Stephen J. "Buscando a Renovacāo: a Nova Onda Administrativa". Revista de Administração de Empresas. FGV. São Paulo. 30 (4): 0521, out/dez 1990.

\section{INTRODUÇÃo}

$\mathrm{O}$ fim do ciclo de governos militares em 1985 e a nova Constituição de 1988 não foram capazes de liquidar a ordem corporativa no Brasil. Com intensidade variável entre as regiões brasileiras, persiste uma das principais características da ordem ou "cidadania regulada" ${ }^{2}$ que é transferir para fora dos locais de trabalho o encaminhamento de conflitos industriais, dificultando a consolidação de práticas de gestão não-autoritária do trabalho e de modernização técnica nas empresas. Face a um amplo processo de "transições", estamos vivendo a difícil emergência de uma "modernidade" laboral e empresarial. Se bem-sucedida, contudo, poderá representar o nascimento de uma nova cidadania no País.

Por transição "no plural" entendo alterações na gestão social do trabalho e mudanças articuladas, ou não, do feitio organizacional com a base técnica. Parto do princípio, assim, que qualquer projeto de "modernidade" empresarial/laboral não poderá adquirir energia catalisadora, se a gestão do trabalho não acompanhar as tentativas-e-erros dos atores industrialistas para constituir nos locais de trabalho (típico locus "público") alternativas a uma recaída no "despotismo fabril" dos anos
70. Associado a esse último aspecto, o país vive uma transição político-institucional do sistema judiciário trabalhista, da estrutura sindical, dos mecanismos de negociação coletiva, e de redefinição de categorias profissionais. Esse texto pretende focalizar justamente essa questão: sem a (re)constituição da cidadania, as "novas ondas" administrativas (participacionismo, desburocratização, qualidade ou "em busca da excelência") serão apanágio dos "ideólogos em ato" (ou seja, dos que detêm o saber competente tecnológico e de humanidades) nas organizações (persistindo seu ilhamento face à sociedade brasileira em estilhaçamento) ${ }^{3}$. $O$ texto percorre a análise de algumas modalidades ou formas de transição nas práticas de gestão no Brasil, e situa um estudo sobre organização industrial em São Paulo, onde está ocorrendo desde meados da década passada uma experiência que chamo de "abertura democrática", associada a uma nova cidadania em (difícil) gestação no País.

\section{MODERNIZAÇÃO EMPRESARIAL E POLÍTICAS DE GESTÃO "REFORIMADAS"}

Para o regime cultural e sócio-político das relações industriais herdado das décadas pas-

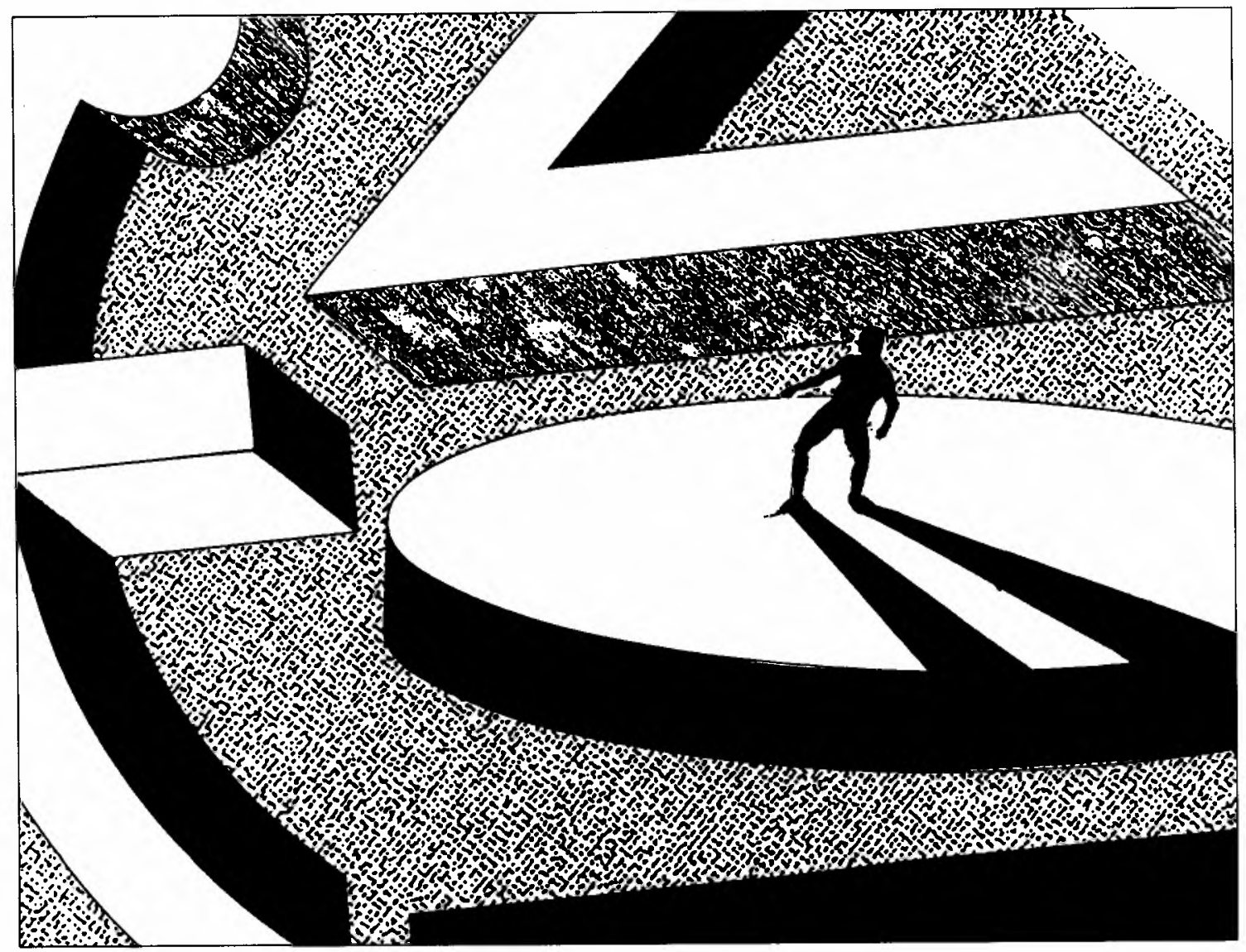


sadas essa transição no plural tem contrapartidas fundamentais em dois sentidos. Um primeiro sentido é de ordem geral: refere-se ao desaparecimento do consenso "corporativista" anterior (pré-1984) entre empresários e regime político acerca da manutenção de um sistema de relações industriais no interior das empresas baseado na rotatividade, rotinização de tarefas e funções, arrocho salarial, e fraca densidade de inovações sociais, organizacionais e tecnológicas.

O outro sentido refere-se ao espaço de manobra nessa matéria que cada segmento, grupo ou unidade empresarial - pequeno, médio ou grande, estatal ou privado, nacional ou transnacional - tende a explorar. Espaço de manobra, no sentido de aceitar, adotar e/ou estimular padrões de modernização social e organizacional no interior das empresas, porém sem admitir isso no plano políticoinstitucional, ou seja, dos "direitos criados".

Esse segundo sentido tem se mostrado estrategicamente seguro do ponto de vista político-institucional para o empresariado: é possível aceitar o esgotamento da ordem regulada (ou seja, não ir contra a realidade), mas é tático gerir esse esgotamento sob as condições efetivas das relações de força com os empregados.

Face a essa dualidade, surgem diversos matizes de gestão: desde as inúmeras situações negativas de reprodução do autoritarismo do passado, até casos de "abertura democrática" de gestão (tal como será analisado adiante). Em geral são experiências de modernização social e organizacional nos polos mais dinâmicos do industrialismo brasileiro (São Paulo, Minas Gerais, Rio de Janeiro, Rio Grande do Sul). Empresários, tecnoburocracia e trabalhadores - em diferentes situações, segundo o ramo e complexo industrial, estão engolfados no que chamo de uma contraditória descoberta da vivência da alteridade nas formas de gestão do trabalho. Por vivência da alteridade na modernização compreendo o processo de ampliação de lugares na mesa de interlocutores do capitalista no espaço "público" de sua organização. (Outros significativos são reconhecidos, como é o caso do operário/operária, quadro técnico-científico/estamento de controle e supervisão, diretorias/empreendedores etc.). Também no espaço político há redefinição de interlocutores institucionais entre o próprio empresariado e trabalhadores ${ }^{4}$. Um dado novo sobre a vivência da alteridade emerge na teoria e na prática relativa à motivação: "não se podendo motivar ninguém, o que resta é facilitar o livre curso da energia motivacional contida no interior de cada pessoa. A maior preocupação se desloca do que fa- zer para motivar empregados para o que fazer para não os frustrar ou desmotivar" 5 .

É contraditória essa vivência de alteridade, obviamente, porque as pessoas descobrem que as práticas de trabalho não estão desvinculadas de sua auto-expressão e da construção de uma nova cidadania. Ora, na medida em que o paradigma anterior de cidadania regulada se encontra em declínio, as pessoas buscam, instintivamente, conhecer o que os "outros" pensam. E se esta busca se depara com a existência local de um movimento transicional entre duas bases técnicas (a convencional e a microeletrônica), mais paralisantes podem se tornar os confrontos entre uma lógica modernizadora e as práticas reais de gestão.

Quando as inovações de hardware, na ausência de alterações na gestão social do trabalho, se configuram como um recurso salvacionista para sair da crise, dois são os desfechos possíveis: a organização morre (ante uma resistência passiva ou ativa, o próprio vencedor sairia derrotado) ou a lógica modernizadora se curva às práticas de gestão "real" do grupo.

Vou me ater à perspectiva desse último desfecho, que corresponde a um conjunto de "sintomas" ou experiências de envolvimento dos empregados com a vida das organizações no País. Que conjunto seria esse, precisamente? Veremos, a seguir as principais modalidades dessas experiências.

\section{MODALIDADES DE CANUIS DE ENOLLVMENTO DOS EMPRECADOS NA VDA DAS ORGANIZAÇÓES}

No Brasil, as tendências gerais relacionadas às práticas empresariais e sindicais de envolvimento dos trabalhadores com a vida das organizações apontam para três grandes modalidades: (a) o canal sindical-operário, com duas grandes experiências nas empresas - os delegados sindicais e as comissões de fábrica; (b) os canais institucionalizados pelo Estado (os únicos casos são as comissões de segurança $\mathbf{e}$ prevenção de acidentes, e os Conselhos de Representação de Empregados nas estatais paulistas); e (c) os canais emulados pelo empresário e grupos técnicos com três tipos de experiências (programas de melhoria de comunicação, programas de colaboração "voluntária", e política de representação interna de empregados). Essas três modalidades de canais empresariais - assim como os três canais como um todo - podem coexistir numa mesma unidade ou grupo empresarial.

\section{A) Canais sindicais}

Dois processos em curso no movimento sindical são importantes para explicar as mu-
4. Essa vivência da alteridade pode ser identificada em inúmeras experiências de formaçāo de uma nova cidadania (ou seu contrário, da morte da cidadania regulada) desde os anos 80: sobre grupos semi-autônomos v. HILLESHEIM, Sergio. et al. Grupos Semi-Autônomos - A Modernizacão das $R e$ laçōes de Trabalho. São Paulo, Ed. Cop. 1989.

5. BERGAMINI, Cecilia W. "Características Motivacionais nas Empresas Brasileiras". Revista de Administração de Empresas, FGV. São Paulo, 3a(4):4152, out/dez 1990 
danças das relações industriais no Brasil. Primeiramente, houve a revalorização política pelo novo sindicalismo brasileiro das relações entre as bases dos trabalhadores nos seus locais de trabalho e os dirigentes sindicais. Em segundo lugar, foram criados mecanismos de consulta e articulação entre os trabalhadores na empresa e o sindicato nos locais de trabalho (ao contrário do padrão de relações operário-sindicais anterior, que não previa ou permitia a presença do sindicato no interior das organizações).

Esses dois processos assumiram, primeiramente, a tentativa de criar a figura do delegado sindical nas empresas, entre 1983 e 1984. Daí em diante as iniciativas mais relevantes ficaram por conta da consolidação de outro canal, as comissões de fábrica. Na medida em que era um canal mais eficaz para cobrir uma série de demandas e reclamações dos trabalhadores sobre condições do ambiente de trabalho, atuação das chefias, ritmo de trabalho, além do aspecto salarial, entraram também em suas pautas (sobretudo nos setores metalúrgico, telecomunicações, bancário, petroquímica) algumas questões específicas relacionadas com modernização tecnológica da produção. Em seu conjunto, são aspectos que delegados sindicais dificilmente poderiam cobrir.

Até o momento no Brasil, há um único agrupamento expressivo de poder sindical que opera com um programa de ação nos locais de trabalho (Central Única dos Trabalhadores, CUT). Por meio de comissões de empresa, esta ação é articulada com sindicatos municipais (ou intermunicipais) e central sindical de âmbito nacional. Entre os demais agrupamentos sindicais - duas entidades "Central Geral dos Trabalhadores", competitivas e um terceiro grupo polarizado pelo maior sindicato de metalúrgicos da América Latina, em São Paulo - apenas o último grupo tem feito esforços para internalizar representações no interior das organizações.

6. Acerca da crise das políticas de segurança dos ambientes de trabalho no País ver RIBEIRO, H. P. e LACAZ, F. Do Que Adoecem e Morrem os Trabalhadores. São Paulo, DIESAT, 1984.

7. No tocante às formas de institucionalização da participação em estatais V. IPEA/IPLAN - Mudança Tenológica, Aumento de Produtividade e Participação dos Trabalhadores em Empresas Estatais. Brasília, IPEAIPLAN, 1990. de participação sindical na sua fase inicial, as comissões de acidente têm eficácia restrita nas mudanças do ambiente de trabalho. Em geral, isso ocorre por não terem possibilidade de alterar processos produtivos e tecnologias obsoletas, responsáveis não só pelo alto índice de insalubridade, acidentes e mortes no Brasil, mas também pelas formas de nocividades externas (como poluição do ar, do solo e das águas) ${ }^{6}$. O segundo caso é dos Conselhos de Representação dos Empregados, que se aplica somente a grandes empresas estatais no estado de São Paulo. Há experiências significativas envolvendo esse tipo de canal, que contêm uma proposta de participação potencial no processo decisório das empresas. As experiências (cerca de cinco ou seis organizações) têm apontado para um problema recorrente, que é a necessidade de enraizamento dos membros do conselho nas demais áreas da organização, sob o risco de o canal ser manipulado ou cooptado pela direção, em nada alterando a gestão do trabalho?.

\section{C) Canais empresariais}

Os canais empresariais têm se concretizado sob três modalidades: (i) programas de melhoria das comunicações internas, (ii) programas de colaboração voluntária e (iii) política de representação dos empregados.

Os exemplos mais avançados nessa matéria podem ser encontrados entre o que se convencionou chamar de "grupo das 500" empresas no Brasil. Esse grupo reúne organizações com mais de mil empregados, que têm os maiores faturamentos do País, e abarca as modalidades existentes de controle de capital (transnacional, nacional, associado com capital estrangeiro e empresas estatais). Em geral, quando se afigura uma "onda" de modernização entre as 500 maiores, essas práticas são repassadas às organizações menores pela tecnoburocracia de administração.

Essas três modalidades de canais surgiram - sem exceção — após 1980/82, quando emergiu o novo sindicalismo no Brasil. Originalmente foram desenvolvidas como uma forma de competição com os sindicatos, nas organizações nas quais o movimento dos empregados (dos trabalhadores e do pessoal técnico-administrativo) se faz mais presente. Há inúmeros programas nessas três modalidades, atingindo coletivos de trabalho nos ramos metalmecânico, bens de capital, automobilístico, informática, siderurgia, processos contínuos, bancos e telecomunicações. Porém, são grandes as defasagens nos aspectos qualitativos das práticas desses canais fomentados pelas empresas. Um exemplo disso: onde pre- 
domina a clássica separação entre pessoal técnico-administrativo e pessoal da produção, não é comum esses programas serem extensivos aos horistas ou trabalhadores da produçãos.

(i) Em grande parte das empresas, o tipo de canal mais comum tem sido o de melhoria da comunicação interna. Também chamados de "programas de comunicação", em geral são metodologias de trabalho com grupos ou indivíduos visando a circular informações vivas detidas pelas pessoas em decorrência de suas posições na hierarquia, ou de suas vivências envolvendo situações de afetividade e qualidade nas relações interpessoais. Esses programas - do ponto de vista da gestão do trabalho - encontram-se, sem exceção, direcionados para facilitar mudanças organizacionais, mas até o ponto de não alterarem a estrutura de poder da organização. Em geral têm utilizado técnicas e psicológicas de dinâmica de grupo.

(ii) Os programas colaborativos individuais são um tipo de canal empresarial que envolve a participação voluntária dos empregados - muitas vezes sob a coação subreptícia das chefias. O exemplo mais destacado é o dos Círculos de Controle de Qualidade... cujo objetivo maior é incrementar o envolvimento sociotécnico do empregado com problemas gerados por mudanças organizacionais e tecnológicas, ou busca de melhoria de qualidade. Portanto, um meio de incrementar a produtividade. Com outros nomes e feitios, esse canal tem sido explorado pelas empresas, competindo com o canal sindical.

(iii) A política de representação de empregados foi tentada no meio empresarial paulista no início da década de 80 , como canal competitivo, e até mesmo substituto do canal sindical. Seu insucesso, enquanto instância para-sindical ou criada unilateralmente por iniciativa do empregador, apontou para o empresariado que programas de envolvimento e participação não poderiam desconhecer o movimento sindical e operário, e muito menos tentar substituir o canal sindical. Os objetivos originais desses sistemas eram: a) desenvolver modelos de representação trabalhista com procedimentos de reclamação; b) organizar os trabalhadores para localizar rupturas e descontinuidades na gestão do trabalho que afetam a produtividade e condições de trabalho e c) competir com os sindicatos. Atualmente é um canal com estratégias mais modestas e visa a objetivos concretos como melhorias no restaurante, transporte, cesta-básica.

Veremos a seguir, a experiência que denomino de "abertura democrática" num grupo empresarial do setor de bens de capital (SEMCO) de origem nacional. Em curso des- de 1987 no núcleo mais avançado do industrialismo brasileiro em São Paulo, essa experiência envolveu entre 1987 e 1990 cerca de 400 empregados, oito unidades de negócio e quatro fábricas.

Alguns indicadores acerca desse "núcleo avançado" do industrialismo em São Paulo e da empresa pesquisada: $40 \%$ do PIB são gerados no estado de São Paulo (cuja área de 248 mil $\mathrm{Km}^{2}$ equivale à da Inglaterra). Com 32 milhões de habitantes e renda per capita de 4,4 mil dólares (1989), São Paulo concentra ainda $50 \%$ da capacidade industrial instalada do País; processa $37 \%$ das exportações brasileiras; produz $67 \%$ do material de transporte, $85 \%$ dos aparelhos elétricos, $87 \%$ do café e $97 \%$ do suco de laranja. Metade da frota nacional de veículos roda em São Paulo. Esse núcleo é composto por milhares de pequenas e médias organizações que estão longe dos parâmetros "oficiais" das 500 maiores. Assim, é razoável tomar o caso de uma empresa ainda que pequena como a Semco e mesmo não estando na lista das quinhentas maiores em faturamento do País - como um exemplo significativo do que médias e pequenas organizações podem fazer, em termos de caminho próprio na gestão do trabalho. A experiência vem tendo grande repercussão na imprensa especializada e não-especializada em São Paulo e no Exterior. Os produtos principais da empresa são bombas e eixos navais, misturadores para indústria química e de alimentos, aparelhos de ar condicionado central, máquinas para fábricas de biscoitos, esteiras industriais, balanças, lavadoras de louça industriais. Faturamento: 30,4 milhões de dólares. Lucro líquido: $450 \mathrm{mil}$ dólares. Relação lucro/patrimônio: 7\% (1990). Outros indicadores do funcionamento da empresa: não existe estabilidade de emprego, mas os critérios para os cortes são apresentados previamente; foi abolido o cartão de ponto e a revista nos corpos e bolsas de funcionários e funcionárias; os horários de entrada são flexíveis, com um núcleo de entrada das 7 às 8 horas para a fábrica e das 7 às 9 para escritórios $^{9}$. Entre prós e contras, a empresa ainda luta para sobreviver: embora tenha produtividade de $60 \mathrm{mil}$ dólares/funcionário - acima da média do setor, que é de $40 \mathrm{mil}$ - seu faturamento é baixo.

\section{"ABERTURA DEMOCRÁTICA" DA GESTÃO dO TRABALHO EM GRUPO INDUSTRIAL PAULISTA}

Por "abertura democrática" entendo a vivência de pessoal de produção, coordenação e projetos em torno dos três canais de
8. Não é possível, aqui, discutir essas variações senão de acordo com as tendências mais gerais.

9. Acerca da experiência SEMCO v. SEMLER "Managing without managers". Havard Business Review, Boston, 67(5):76-84, sept' oct. 1989 e NEDER, R. T. "A Crise do Industrialismo, Produtivismo e Democracia Estudo de Caso sobre Participação de Trabalhadores e Tecnoburocracia no Brasil". Relatórios de pesquisa de campo FGV/EAESP/NPP 1989; FFLCH/USP/CNPQ 1990/91). 


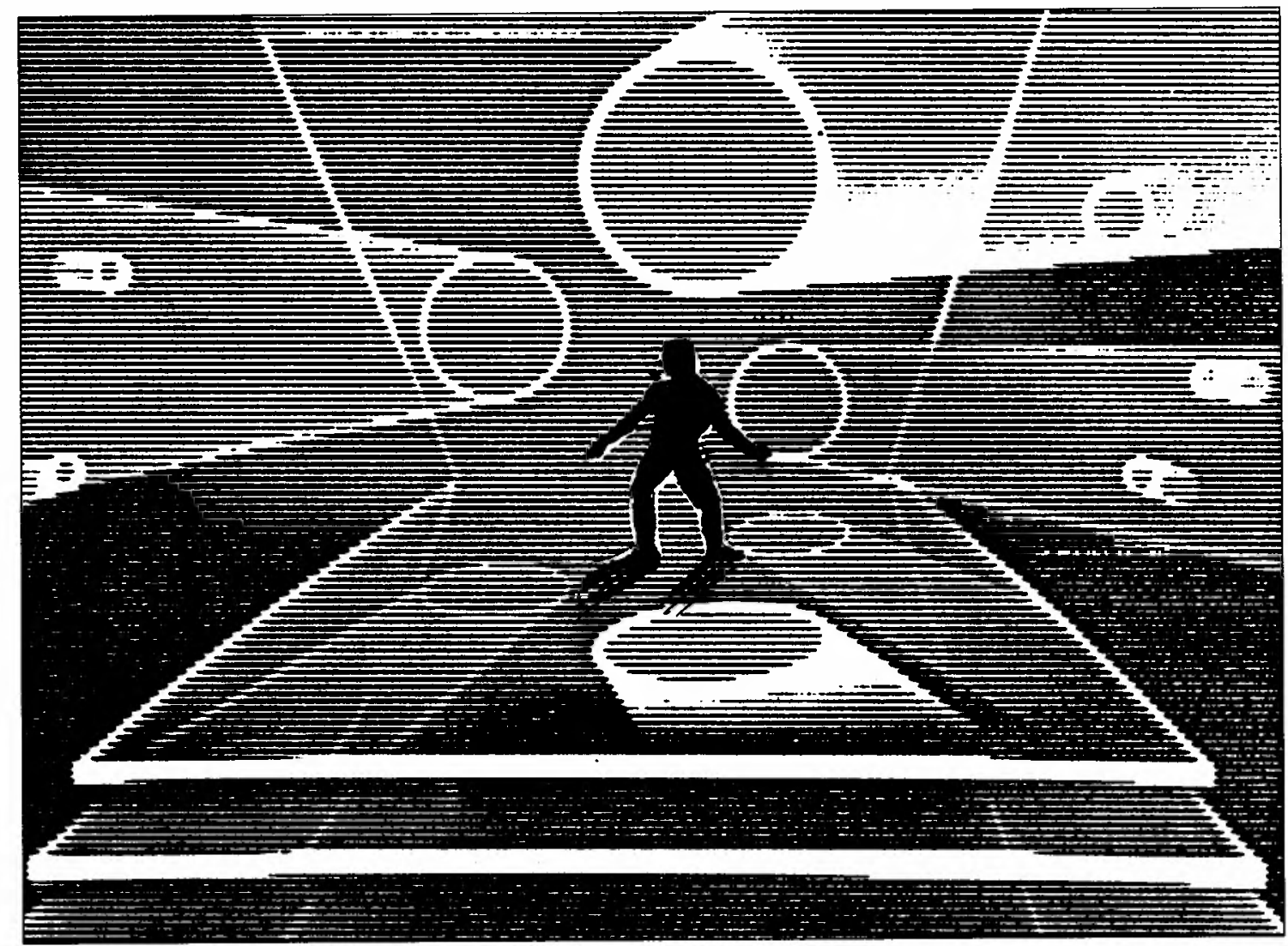

envolvimento, de forma sistemática e simultânea, com a vida da organização.

Três medidas inauguraram essa abertura da gestão: formação pelos empregados de comissões de fábrica; unificação do contrato de trabalho de todos os funcionários (é eliminada, assim, a tradicional separação nas empresas industriais brasileiras, entre empregados com remuneração por hora e os demais, mensalistas). A terceira foi a criação de um sistema de participação nos lucros extensivo ao conjunto de empregados e administrado por comissão paritária. A essas "aberturas" seguiram-se outras, totalizando onze canais de expressão entre 1989 e 1990. (Tais experiências, que qualifico de "canais de auto-expressão e envolvimento dos empregados" com a vida da organização, envolvem o sistema de participação nos lucros, comissão de melhorias nos restaurantes coletivos, prefeitura das unidades do grupo, programa das mu-

10. Dados de pesquisa de campo de NEDER, R. T. "A Crise do Industrialismo, Produtivismo e Democracia - Estudo de Caso sobre Participaçāo de Trabalhadores e Tecnoburocracia no Brasil". Relatórios de pesquisa de campo FGV/EAESP/NPP - 1989; FFLCH/ USP/CNPQ - 1990/91. lheres, grupo de melhoria do meio-ambiente, grupo de economia ou racionalização, grupo de avaliação de qualidade, sistema de avaliação de chefias, seminários com temáticas abertas, comissões de fábrica e comissões internas de prevenção de acidentes) ${ }^{10}$. postos de trabalho ocorreram no sentido de
As mudanças na estruturação formal dos encurtar a distância entre o topo (processo decisório) e a produção direta/apoio administrativo. A hierarquia de controle ficou mais achatada, reduzindo-se a um degrau a distância entre o trabalhador da produção direta e a direção máxima de cada unidade. (Antes eram dois ou três dependendo da área). Assim, entre a base (produção direta e administração) e o núcleo de tomada de decisão somou-se uma faixa correspondente às chefias intermediárias. Criaram-se as figuras de "associados" (ex-operários, líderes, funcionários administrativos, mestres e encarregados administrativos), "dirigentes" (pessoal de chefia operacional e técnica de nível médio e superior) e "sócios" (ex-diretores de unidades). No topo onde estão os "conselheiros" que correspondem ao núcleo de tomada de decisões (do qual participam diretamente os sócios e, indiretamente, os dirigentes).

O processo decisório passou a adquirir um duplo sentido: reúne os que ocupam funções decisórias de chefia no topo da organização do grupo, com funções explícitas de planejamento e definição de novos projetos e linhas políticas válidas para todas as unidades do grupo, e também os que ocupam essa função no âmbito local de uma unidade. Além disso, o processo decisório abarca também uma 
dinâmica de reuniões e encontros de regularidade variável, das quais participam os associados e dirigentes. $O$ dirigente passou a ser, na nova estrutura, o elo de ligação com a base (trabalhadores na produção direta e administração) antes e depois das tomadas de decisões. Seu significado é combinar o tradicional "critério topológico" do controle hierárquico (qual seja, decide quem está no alto da hierarquia) com o "critério cinético", relativo a quem está no controle direto dos processos de trabalho e gestão (qual seja, também decide quem está em contato com o movimento real do processo de produção direta/indireta).

Após três anos de experiências, as principais mudanças ocorridas envolvendo as onze vias de expressão e envolvimento dos trabalhadores com a gestão da empresa, houve a fusão de algumas vias, supressão ou continuidade de outras. Os parâmetros efetivos para fusão/supressão/continuidade dessas vias foram três: grau de aceitação do sistema de participação nos lucros entre o coletivo de empregados; grau de eficácia das vias de auto-expressão no processo decisório e grau de maturação das experiências do canal sindical/operário (comissão de fábrica ou empresa).

O sistema de lucros - do ponto de vista sociotécnico - foi implantado a partir de uma estratégia inicial: demonstrar a decisão de que a "abertura" começava pela divisão de lucros (restrita a situações de balanço positivo). Surgiu, assim, a necessidade de os representantes dos empregados realizarem a leitura do balanço. Isso vem exigindo cursos regulares dos representantes ligados a Comissões de Fábrica e Comissão de Gestão do Fundo de Participação, conduzidos por organismo externo, de natureza intersindical (Departamento Intersindical de Estatísticas e Estudos SócioEconômicos). Na perspectiva da participação política, a leitura do balanço é um "ponto no tempo", um retrato estático do que a organização alcançou no período. Outra dimensão, entretanto, no entendimento desse resultado contábil, é a compreensão de "como" a organização aportou aí. Nesse caso, a dificuldade maior está justamente na discussão e recuperação dos aspectos que envolveram problemas de gestão, custos, de venda no mercado, crise econômica e recessão.

A ênfase total dessa estratégia está, obviamente, na mudança da gestão social do trabalho e em técnicas organizacionais. Além de um processo, abortado, de implantação de sistema informatizado para produção (MRP-Material Requirement Planning), há pouca inovação tecnológica com base na microeletrônica na produção e nos fluxos de informação. (Mais recentemente, em 1990, foi criado um grupo de ex-dirigentes, responsável por proposições nas áreas de capacitação tecnológica, inovações de processos e produtos).

Por certo que as mudanças antes descritas envolvendo a estrutura decisória - tomada como noção topológica e cinética simultaneamente - ao provocarem um encurtamento da pirâmide, nem por isso deixaram de reproduzir, em escala menor, a separação tradicional entre planejamento e execução. Como a organização lida com esse problema?

Essa questão está relacionada com uma das linhas estratégicas de mudanças relativas à criação de práticas de politécnica dos empregados, entendidas como as que visam a envolver o funcionário num aspecto mais amplo de atividades diretamente relacionadas com seu núcleo de funções. Isso quer dizer que a politecnia se define no âmbito imediato das funções atribuídas ou prescritas ao empregado. Gradativamente, elas podem incluir atividades ou segmentos de atividades relacionadas a outras funções interligadas pelo processo de trabalho na produção direta ou indireta, ou ainda a coordenação e projeto.

Entre o segmento de dirigentes essa politecnia já estava ocorrendo no período estudado (1989/90). Nesse grupo, as tarefas de planejamento e execução eram abordadas por tentativas, como experiências de politecnia. Dada a distância menor entre dirigente e associados proporcionada pelo novo organograma, grande parte dos problemas cotidianos de produção pode ser discutida e resolvida entre esses dois segmentos. A intenção proposta pela "abertura" da gestão social foi tornar os associados sensíveis a essa expansão de sua "especialização" imediata, até abarcar segmentos de funções de especialidades análogas (exemplo: um torneiromecânico especializado numa fresadeira ampliaria suas atividades para controlar também máquinas de mandrilhar, perfurar etc.). As experiências nesse campo coincidiram, ainda, com inovações organizacionais como células de manufatura, Kanban e racionalização de estoques.

Esse esforço tem encontrado resistências dos trabalhadores da produção direta, o que se deve a uma cultura de "operário especializado ou de ofício" (desconfiança frente a um esquema que pode representar maior volume de trabalho, sem contrapartida na remuneração). Essa resistência é ainda ratificada pelo sindicato, que se posiciona contra essa políti- 
ca de polivalência. ( $\mathrm{Na}$ medida em que a atual política de remunerações no mercado mais amplo segue as prescrições consolidadas de especialização por tipo de ofício, o sindicato se apega ao que é mais concreto e palpável, na hora de fazer negociações no "atacado", para grandes grupos profissionais).

\section{O SIGNIFICADO DESTAS MUDANÇAS}

Os canais que funcionam no âmbito empresarial configuram um caminho de mão dupla. Por eles transitam - em primeiro lugar e hierarquicamente - pessoal gerencial, técnico e administrativo, enquanto população-alvo dos programas de envolvimento sóciotécnico. Certas organizações estão "abrindo" tais programas (em grande parte tributários de modelos europeus, japoneses e norte-americanos preconizando fórmulas ou receitas para melhoria das relações industriais). Nesses casos eles atingem também os trabalhadores.

Nesse mesmo caminho, deparamos com um cruzamento fundamental. Os programas "participativos" - que vêm sendo impropriamente, a meu ver, chamados de "novas tecnologias sociais" - buscam ajustar-se a processos empresariais mais amplos de introdução de novas tecnologias de base microeletrônica, surgindo daí a necessidade de calibrar mudanças técnicas com mudanças organizacionais.

Tais ajustamentos são teoricamente básicos do ponto de vista da criação de "clima" trabalhista e organizacional para evitar rejeição das mudanças geradas pela transição da base técnica. Entretanto, os resultados desses programas - em diferentes organizações - são questionáveis sobretudo por um aspecto. Como muitas experiências recentes no Brasil vêm demonstrando, tais programas que buscam "qualidade", "excelência dos produtos", "melhoria do clima organizacional" ou "renovação das relações humanas" fracassam entre os trabalhadores pela dificuldade de realizar uma efetiva vivência da alteridade com canais operário-sindicais (quando existentes) de expressão e envolvimento. (Os casos mais evidentes de fracasso desses programas, ocorridos simultaneamente às mudanças da base técnica, vêm se dando no complexo industrial das montadoras automobilísticas) ${ }^{11}$.

Esse processo, em si, nada tem a ver com a capacidade da ação operária e sindical nos locais de trabalho. Entretanto, para o bem ou para o mal, a confluência desses dois processos está afetando as relações industriais, os conflitos entre sindicatos, empresas e Estado. Vem provocando, sobretudo, um fenômeno micropolítico extremamente relevante, que é a possibilidade - entre trabalhadores e os "intelectuais das organizações" ou os quadros técnicos - de reinstaurar a vivência de espontaneidade nas relações sociais do trabalho em situações de mudança nãoplanejada.

Nesse último sentido é que adquire relevância o caso "Semco" em São Paulo. Ele configura um "polo" de experiências de envolvimento dos empregados com a gestão da empresa, de caráter sociotécnico. Sua principal marca é fazer os empregados superar o posto de trabalho como referência central de ligação e identidade com a empresa. Essa superação deve ser entendida, porém, como o gradativo enriquecimento de tarefas (na tradição da escola sociotécnica escandinava) do posto de trabalho, tornando-o uma referência obrigatória de capacitação do indivíduo com relação a seu trabalho. Uma vez alcançado esse estágio - variável em cada coletivo de trabalho e mesmo individualmente o envolvimento sociotécnico é ampliado para questōes que envolvem o ambiente externo ao posto de trabalho. Isso pode tornar o empregado atento não só ao que acontece nos postos vizinhos (o que não seria novidade) mas às mudanças externas a sua produção imediata, conectando-o com outros segmentos de atividade (planejamento imediato das atividades cotidianas, questões relativas ao restaurante, qualidade do meio-ambiente ocupacional, situação das vendas e faturamento, questões salariais e critérios de remuneração, reclamações do segmento feminino). Esse movimento para fora do posto de trabalho lhe permite vivenciar outros "papéis sociais".

As indicações empíricas levantadas pela pesquisa de campo durante 24 meses, com todos os segmentos do coletivo de trabalho dão conta que parcela significativa das pessoas na produção direta e indireta encontra-se bem informada sobre o que acontece de importante nos diversos segmentos. Essa informação é obtida através das vias de auto-expressão e envolvimento (canais empresariais, sindical e legal antes citados).

Assim, uma segunda questão diz respeito à vivência pelas pessoas de novos papéis, com a conseqüente diferenciação do seu rol de papéis no interior da organização. Essa diferenciação, que em muitas experiências internacionais é corrente, afigura-se para o caso "Semco" como relevante: grande parte das dificuldades de gestão sob um estilo "patriarcal", existentes na primeira metade da história da organização (anos 1960/70) deixou de existir com essa estratégia de dife- 
renciação de papéis. (Embora eu tenha reservas a explicar um processo de mudanças numa organização empresarial por relações sociais estritamente internas, parece não haver dúvidas de que essa diferenciação está gerando um processo de mudanças).

Como terceira questão, é possível problematizar o que os trabalhadores e a tecnoburocracia envolvida podem fazer com essa diferenciação de papéis e maior grau de informações. Isso diz respeito à cidadania, ou à natureza da participação política. Em que medida os segmentos - tecnoburocracia e trabalhadores na produção direta/indireta - encontram-se efetivamente organizados como atores políticos engajados na "abertura" da gestão da empresa?

Creio que esse engajamento interno não seja homogêneo e esteja mais concentrado no topo da organização e nas principais lideranças intermediárias e de trabalhadores. Mas há uma perplexidade - misto de incredulidade e espanto - na maioria das pessoas entrevistadas nos segmentos tecnoburocráticos e de trabalhadores para saber onde está o poder: se no posto de trabalho, no processo decisório, ou num terceiro lugar, percebido difusamente como o "mercado".

Certamente - nesse caso pesquisado não é mais o controle do posto de trabalho o centro da disputa do coletivo de trabalho. Ele não chegou a ser esvaziado, mas seu potencial foi transferido - primeiramente - para a questão de como são tomadas as decisões e das limitações do pessoal da produção direta e da indireta para trabalharem juntos (há dificuldades) em matéria de co-gestão.

Nesse último aspecto encontramos a questão da especialização que conduz maior acesso ao processo decisório. Na medida em que a política interna de "politecnia" reestrutura as especializações, é certo que os grupos mais avançados nesse processo - a camada da tecnoburocracia - podem retirar daí maiores benefícios. Relacionado a essa questão da especialização, está o "terceiro lugar" do poder enquanto um complexo de relações que se estende do interior para fora em direção ao "mercado". Na medida em que a diferenciação de papéis pode ser empobrecida na luta pela sobrevivência econômica em meio às incertezas do mercado, esse aspecto ainda aparece obscurecido. Ele não chega a ser percebido como a fronteira concreta das dificuldades das pessoas. Dessa forma, as relações de trabalho "reformadas" nessa organização, no momento pesquisado, pareciam caminhar para um envolvimento dos empregados nas questões do mercado.

\section{CONCLUSÃO}

A título de conclusão geral, eu diria que as relações industriais no Brasil passam atualmente por um efeito "sanduíche" com diferentes camadas de problemas: esgotamento da ordem política entre trabalhadores e empresários regulada pelo corporativismo; novos paradigmas de organização do movimento sindical e operário, renovação dos modelos de gestão sob o impacto das influências vindas do exterior e alterações nos paradigmas tecnológicos dos principais complexos industriais. Mas esse quadro tem aspectos tanto semelhantes quanto diversos do que ocorre em sociedades industrialistas na Europa.

Do ponto de vista dos valores políticos e culturais, é inegável que a famosa "ética do trabalho" sob o capitalismo e o culto da "produtivismo" sob o socialismo, configuram uma "fase heróica" de industrialização (da Primeira Guerra Mundial até os anos 60). Alemanha, Inglaterra e Japão (para não falar da União Soviética) talvez sejam experiências extremas (no pós-guerra) de (re)industrialização, construídas sobre bases político-ideológicas muito diversas, mas idênticas quanto ao apelo "heróico" ao industrialismo, como ethos fundante das relações entre trabalhadores e elites industriais.

Atualmente, entretanto, em muitos sentidos estamos assistindo ao declínio da utopia da sociedade do trabalho construída sob o ethos heróico ${ }^{12}$. À medida que os valores de uma sociedade de consumo de massa ou fordista - sob a hegemonia norte-americana - se instauraram, foram sendo construídas outras formas de aglutinação de interesses entre os atores industrialistas (além de trabalhadores e empresários, também desempenham, agora, papel-chave, camadas técnico-científicas). Sob o signo do tempo livre, da evasão e do lazer, porém, os atores industrialistas já não compartilham uma base ideológica comum de inspiração produtivista (típica da fase 1945-70). Surgem novos perfis qualitativamente diferenciados de consumo; os movimentos sociais de inspiração ambientalista e ecológica geram rebatimentos sobre o ethos heróico do passado. (A meu ver, a busca de uma teoria que oriente a prática do "ecodesenvolvimento" não está dissociada da emergência de novos sistemas produtivos como a produção flexível em massa, ou toyotismo; ambas as frentes operam nos limites desse esgotamento sócio-cultural que a morte do produtivismo proporcionou $)^{13}$.
12. Ver, a propósito, GORZ, André. "Quem não tiver trabalho, também terá comida". Estudos Avançados. USP. NN. 10. abril 1991 HABERMAS, Jurgens "A' Cultura ocidental e a perda de confiança em si mesma". Rev. Presença. Rio de Janeiro. $n^{\mathbf{0}} 9$ fev. 1987 ; $\mathrm{e}$ OFFE, Claus. "Trabalho: a categoria-chave na sociologia?". Revista Brasileira de Ciências Sociais, 4, jun de 1989.

13. 0 debate sobre tecnologias alternativas (v.g. GARCIA, Ramon M. "Tecnologia apropriada: amiga ou inimiga oculta?". Revista de Administração de Empresas. 27(3):26-38, jul/set 1987) ganha novo impulso com o declínio do fordismo, mas adquire outros adversários com a emergência da manufatura flexivel em massa. (v.g. FERRO, José R. 'Aprendendo com o 'Ohnoismo' (Produção Flexivel em massa): liçoes para 0 Brasil". Revista de Administraçāo de Empresas. São Paulo. 30(3):57-68, jul/set 1990). 
No Brasil, a fase de modernização com indústrias de consumo de massa foi marcada, até 1984 , por um regime político que a instaurou sob um manto supraclassista, por vias anti-constitucionais, e apelando aos "interesses nacionais", associando isso a um novo Eldorado do consumo, num clima, porém, de repressão dos conflitos industriais. Hoje, os apelos são - ou devem ser - outros. Já é difícil encontrar nos países de industrialização avançada, desde fins dos anos 60 , a "ética do trabalho" ou a crença numa sociedade industrializada como sinônimo de pleno emprego. $\mathrm{Na}$ sociedade brasileira atual essa ausência começa a apresentar seus inúmeros rebatimentos (entre outros motivos, pelo esgotamento do modelo de cidadania regulada, forte desregulamentação promovida por um governo neoliberal, políticas de recessão, difícil obtenção de apoios políticos para a reestruturação industrial e das relações industriais).

Assim, a modernização no Brasil - se bem-sucedida na atual década - acompanhará as tendências de redução da oferta líquida de emprego nos setores dinâmicos e tecnologicamente competitivos. Para a formação social brasileira isso significa que vamos vivenciar a sobreposição de problemas históricos gigantescos (persistência de altíssima concentração da renda pessoal e funcional, falência do sistema educacional associada ao analfabetismo, miséria rural e urbana, degradação dos recursos do meio-ambiente por uma industrialização tecnologicamente atrasada, e a inexistência, para metade da população, de qualquer cidadania) com outro patamar de problemas. Patamar esse, relacionado com um tipo de organização da produtividade associada a uma nova base técnica que aumenta o rendimento do trabalho, ao ponto de tornar desnecessário engajar na produção e nos serviços, contigentes importantes da população economicamente ativa. Se é relevante, atualmente, o debate sobre um novo padrão de financiamento dessa modernização, não me parece suficiente assumir que a sobreposição de problemas poderá ser equacionada ex-post ${ }^{\text {(14). }}$.

Essa tendência opera no Brasil sob um dinamismo análogo ao chamado efeito dominó, segundo o qual a reduzida oferta de emprego nos setores de industrialização moderna é compensada pela maior oferta (com qualidade inferior) de postos de trabalho nos setores tradicionais em outras regiões brasileiras (inclusive de fronteira agrícola).

Com o atual paradigma das novas tecnologias, os segmentos não-empregáveis nos setores modernos também dependerão dessa relação perversa. Enquanto isso, em muitas regiões do país (Nordeste, CentroOeste e Amazônia) vastos contingentes da população economicamente ativa continuarão em condições não empregáveis permanentemente e à margem da cidadania política.

A questão crucial que os diferentes sindicalismos enfrentam no caso brasileiro praticantes ou não da cidadania regulada, seja na vertente do "novo sindicalismo" ou na do "sindicalismo de resultados" - é a mesma: decresce a força de aglutinação da utopia do trabalho, como valor capaz de estruturar as relações sociais entre as pessoas. Com isso, é reduzida também a força de atração dos sindicatos. Decresceram nos anos 80 os contingentes sindicalizados nos principais países europeus e Estados Unidos. No caso brasileiro, cuja taxa de sindicalização em relação à população ocupada é historicamente baixa (embora tenha havido grandes índices de crescimento da sindicalização entre 1970 e 1980 por conta de índices baixos de partida), ampliar as bases sindicalizadas continuará a ser uma questão de vida ou morte para as organizações dos trabalhadores. Atualmente, esse problema também recebe a convergência de outras tarefas relativas a dar resposta à tendência de penetração de novas tecnologias no trabalho industrial, serviços bancários, de telecomunicações, comerciais e de escritório, e setor governamental. As demandas, nesse caso, mudam de tom. Torna-se urgente, paralelamente às políticas de defesa dos interesses econômicos tradicionais, saber questionar o conteúdo institucional e as políticas internas de gestão nas organizações que passam pela mudança de sua base técnica.

Sob o reino das "transições", portanto, está em pauta no Brasil - para os diferentes atores industrialistas - a prática de um outro tipo de cidadania (sobreposta à "regulada", que não chegou a existir em vastas regiões do Nordeste e Amazônia). Trata-se do exercício de uma cidadania ativa. Em poucas palavras, ela significa que quem melhor e mais extensamente se organizar, maiores oportunidades deterá nas negociações locais e coletivas. Por isso mesmo, não basta que as novas ondas administrativas sejam capazes de provocar "mudanças" nas organizações. Suas aplicações, em articulação com novas tecnologias, podem se revelar inócuas e destituídas de sentido para os empregados, caso não atendam a um requisito básico, que é a mudança de qualidade da gestão social do trabalho. $\square$ 